\title{
REHABILATION AND MAINTAINANCE OF ANCIENT BUILDING- A CASE STUDY OF SURGUJA DISTRICT
}

\author{
Aradhna Shrivastava \\ M. Tech (Structural Engineering) \\ Vishwavidhyalaya Engineering College (Surguja University), \\ Ambikapur, Surguja, Chhattisgarh, India \\ Vijay Kumar Shukla \\ Assistant professor Civil Engineering Department \\ Vishwavidhyalaya Engineering College (Surguja University), \\ Ambikapur, Surguja, Chhattisgarh, India
}

\begin{abstract}
In this paper we are going to study about the failure of traditional buildings structure like cracks in beam column slabs or failure of these component due to various reasons like permanent loading, creep, temperature stress, shrinkage, settlement of foundation, moisture. In this study we will classify the type of failure in component and suggest the method to rehabilitate the component without changing its homogeneity. Study has been to implement the method for the restoration of building with original material keeping in mind that material deviation do not help in proper boning of component.
\end{abstract}

Keywords: Repair work, lime surkhi component, historical building, rehabilitation technique. Raghunath Palace, Circuit House, Kothi Ghar

Cite this Article: Aradhna Shrivastava and Vijay Kumar Shukla, Rehabilation and Maintainance of Ancient Building- A Case Study of Surguja District, International Journal of Advanced Research in Engineering and Technology, 10(1), 2019, pp. 160 168.

http://iaeme.com/Home/issue/IJARET?Volume=10\&Issue $=1$

\section{INTRODUCTION}

Repair and restoration project for any historical building is necessary and a very important task. It is easy to rehabilitate the concrete structure as lots of method, materials and technologies are present but traditional buildings are not composed of cement materials they are constructed by use of local available materials like lime surkhi, mud, stones, and along with them edible food materials as admixtures and fillers, which now a day are not in practice.

To rehabilitate any ancient structure we have to take care of many parameters so that building integrity is maintained and its importance get increased. Cement concrete building 
repair is easy as well as economic but traditional building repair is a tough task as during the repair work what parameter arise at site no one can either imagine because buildings part are sometime partially damage and sometime completely which by visual inspection cannot be possible. Nor even sometime special damage detection technique could do that because these techniques are designed for cementitious materials not for traditional materials.

The building has suffered a lot of deterioration. It has suffered from fire hazard, moisture effect, chemical attack, settlement, and biological attack too. Its restoration is important because it has our district rich History. It has been constructed using lime surkhi which is not in practice currently. So its restoration is a difficult task.

The main aim of research is to find out the alternative to restore the palace which remind us about our rich heritage so that our upcoming generation also learnt how our state was a prosperous one.

This case study is about Raghunath palace, circuit house, Collectorate building restoration without changing its homogeneity and structure design so that it can withstand many more years. The building has crossed its serviceability age but it is important for us as it reveals out the rich heritage of Surguja province. The building has suffered damaged due to weathering action, fire, moisture, and defect in construction due to which settlement occur. Prior to actual repair of building decision of repair work has to be carried out so that we can frame out the materials requirement labour requirement, capital requirement and time taken up by us to do the repair work. Certain important aspects should be kept in mind while deciding the repair work that structure should not lose its originality and its strength should also get increased with increment in durability and taking care of precautionary measure for worker is must.

\section{METHODOLGY AND MATERIALS REQUIREMENT}

\subsection{Materials}

For the repair of palace and other structure the materials which we will need are lime either hydraulic or limestone, wood apple extracts, Sal wood, bricks, steel girder of Tata company of required dimensions. Lime surkhi mortar will be prepared either by hot kiln process or hydraulic lime which is available now a day easily in powder form and its component can thus be easily made.

\subsection{Methodology}

The restoration of building should be done in accordance of

a) First visualizing the damage and identifying the most critical portion of building which should be repair first.

b) Evaluating the damages and giving priority to those repair work which is most vulnerable like in this case settlement and roof damage.

c) Selecting the methods which is best suited for the restoration of particular type of damage and arranging materials for the same.

d) Implementing the method selected for the damage repair work and taking precautionary measure to avoid future damage as well as to workers while working.

I. Damage to roof- The roof of the building at various places got damaged as it is made up of brick and rested upon wooden girder. The white ants ate up the wood and made it empty from inside, moisture presence rotten up the wooden edges which were rested on the brick walls. And due to fire many of the wooden batten and purlins get completely damaged which in turn leads to falling of roofing materials. Bricks are laid vertically in between the batten as shown in figures fall off where battens were completely damaged. 
The wooden beam at center portion are not destroyed but at end they have to bear the shearing force and destruction is due to sagging of beam which leads to copllaps of building as on wooden whole roof has been rested.

Repair work that should be carried out to overcome the above problem- divides the whole palace into part by part and repair should be done separately for each portion.

a) Remove the roofing materials without damaging the bricks and tiles of the roof and properly wash them if some unwanted materials get deposited over them. And stalk them separately.

b) Change the batten, purlins, and wooden girders which are completely damaged by new ones keeping in mind the dimensions and type of wooden material used in the building. It is of sal wood.

c) Properly seasoned and painted timber which should match the original colour should be placed.

d) After placing appropriate wooden materials lay down the bricks over the batten with the help of lime mortar and apply lime mortar above the bricks to place the roof tiles which we have kept during removal of roof.

e) If bricks are less in number then use other place roof brick so that one kind of bricks should be placed in one place and arrangement of tiles should be such like the previous arrangement.

f) New beam which we have to place on the end should be properly glued or scarfed with the older one which are still in good conditions.

g) Jointing between the older and newly beam should be at a longer distance.

h) For placing beam in the wall holes should be made and epoxy of lime mortar should be injected in the wall bore holes so that wood should be properly bonded with the mortar and is able to transmit the load. After hours of epoxies setting framed should be removed and then the surface is matched with the original one for final touchup.

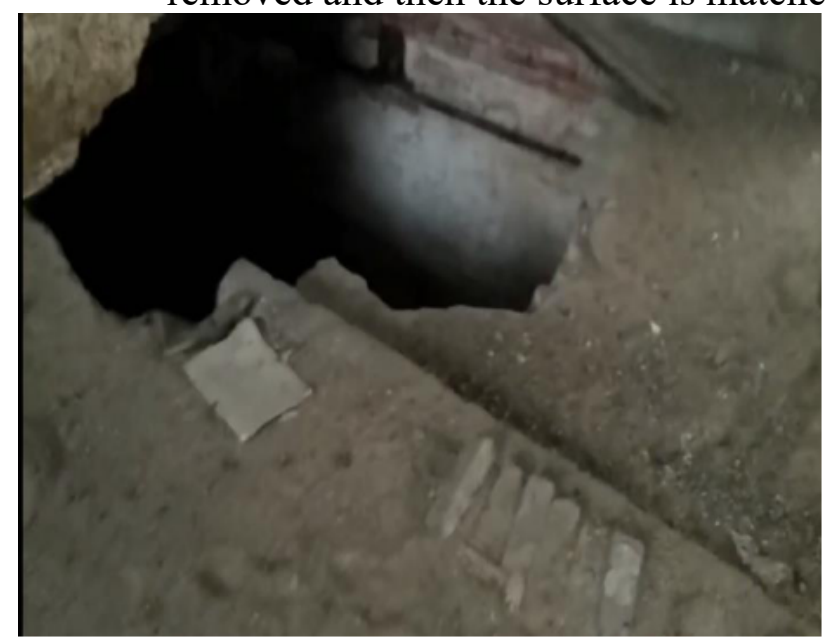

Figure 1 a) Roof damage at palace

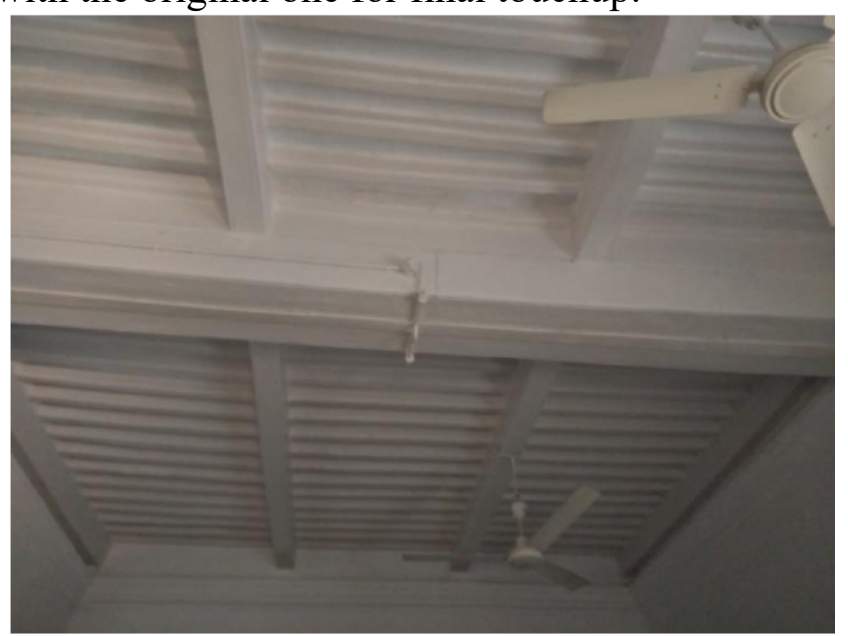

Figure 1 b) Repaired roof At Kothi Ghar

II. Settlement problem-At the time of palace construction no one actual gave due importance to the soil bearing capacity. Because at that eras of construction people were unaware of such matter. At many places we have observed that the settlement of wall has occurred and sinking of soil beneath the wall leads to crack problem. These are due to poorly compaction of soil, moisture content or drainage leakage under the soil.

Repair work that should be carried out in order to remove the settlement are 
a) First of all check the drainage and water leakage problem of the palace and repair if any present.

b) Arrange proper disposal of rainwater which fall in the palace courtyard that it should not go inside the rooms.

c) When we visually inspect the palace we have not found serious foundation settlement issue as slight settlement had occurred at few place of structure which can be corrected using normal methods.

d) Peel of the floors where settlement issues are present and check out for bores or holes due to rats and any other animals if present. But before this support the corresponding roof with temporary column and support so that wall if required to be repaired at bottom will not affect the roof or superstructure.

e) Properly compact the soil and remove all the agents which cause the settlement at that place and reconstruct the wall of palace as the walls are too wide more than 4 feet at plinth thus additional components are not required to support the walls.

f) Mud jacking or grout pumping should be done if at any place soil is found to be expansive.

g) Piling is required if complete foundation failure has occurred due to which hard strata will be constructed after boring holes and drilling in such a manner that vibration is nearly negligible. And then wall erection should be carried out.

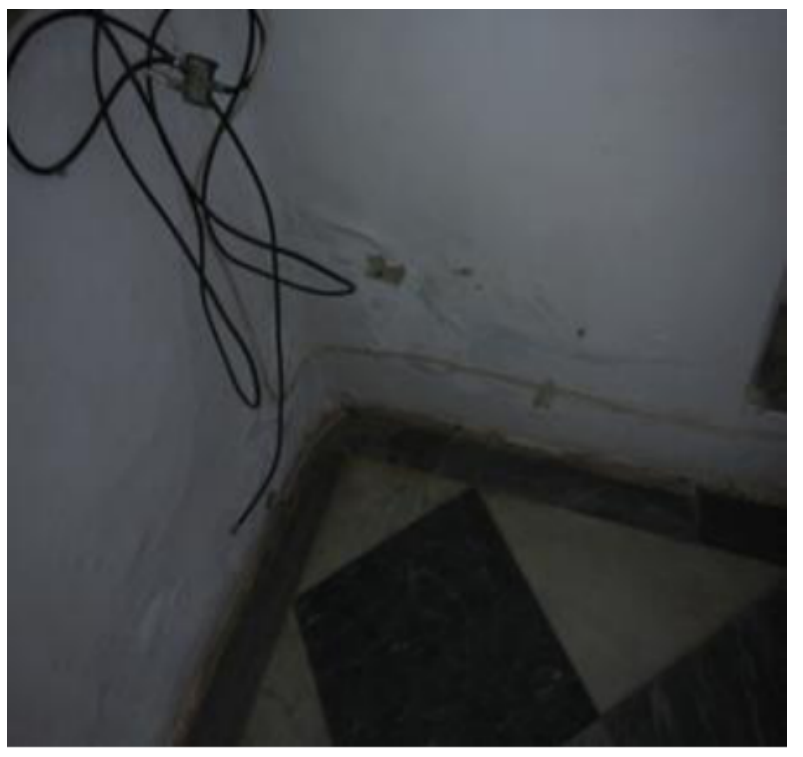

Figure 2 Soil consolidation leads to Settlement

III. Damage to Walls- at various places portion of wall gets completely felled of which slowly leads to brick deterioration as internal portion of wall get exposed to environment. Lack of care leads to collapsing of walls. At certain places small plant arises which disintegrate the bricks leading to wall failure.

Remedial measure that should be taken to repair the wall are

a) First of all remove the plaster and paint coating that is present over the damaged wall at about 2 feet and remove all the damaged bricks. Never use such brick for any other repair work because they have lost all its strength to moisture exposure and termite attack. 
b) After the removal of brick make lime mortar mixed with wooden apple and with the help of new brick complete the wall that is damaged by proper joining the exixting construction and new construction.

c) Lime surkhi mortar if possible to make then it is best as the structure is made up of same mortar and these in turn give good bonding strength between existing wall and new wall.

d) After proper curing apply lime mortar plaster and do whitewashing by lime to get even shade as before.

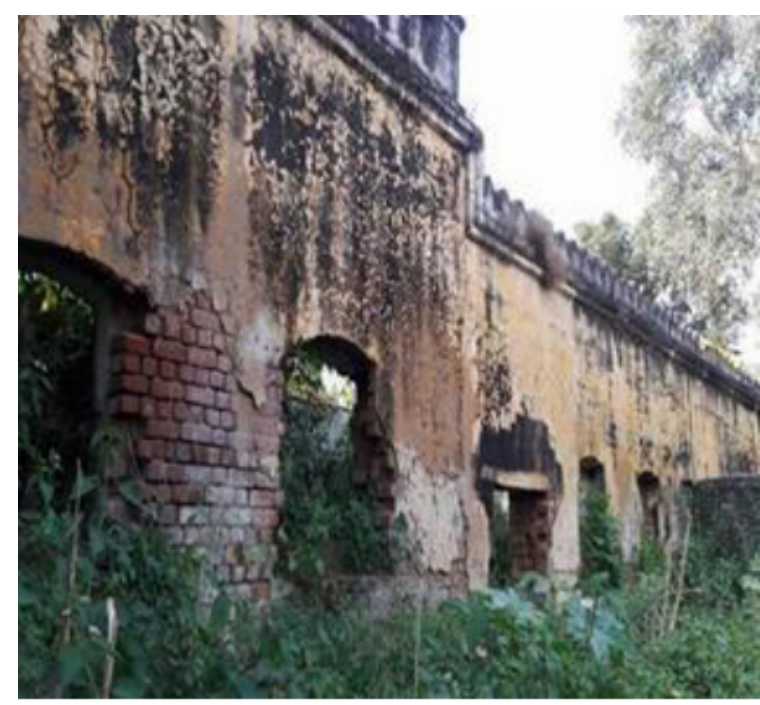

Figure 3 a) Damages to External walls

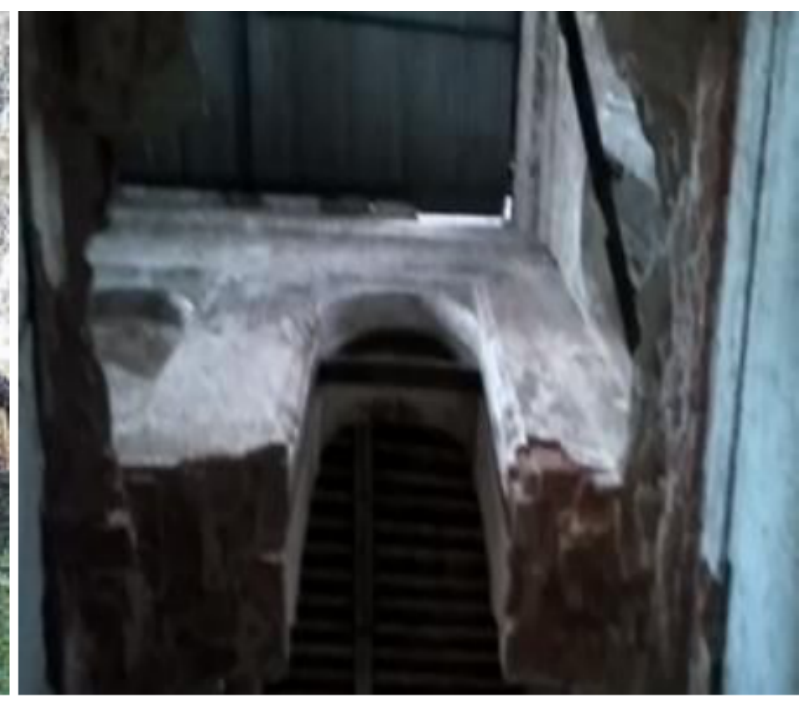

Figure 3 b) Roof and internal wall Damage

IV. Cracks-certain cracks are only at the surface of wall that is only on peripheral portion that can be easily repaired but certain cracks are structural cracks which required utmost importance and should be repaired carefully. Hair line cracks are the defect due to less curing of structure component or due to not having proper bonding with the other component but major cracks are arises due to construction defect, sinking of foundation, or insect which make bore inside the wall and other component.

As the palace is load bearing and not concrete materials are used it has large sized walls which support the roof. At various places these wall get serious cracks at jointing area between roof and wall, girders and walls as girder rest on these heavy walls.

Repair of such cracks can be done as

a) Remove and wash the plaster and painting over the walls and select those cracks which are structural in nature which require due importance of repair.

b) Make hole by drilling all along the cracks lining and wash it off and allow it to dry.

c) If it is not deep crack then use epoxy grouting or impregnation to seal the cracks. The epoxy should be of lime so that it can combine and create strong bond with the existing masonry layer in between walls.

d) C-pins, U-pins or stitching will be used for deep cracks when we will require to provide tensile strength and it is should be used in places where cracks are wider and deeper.

e) If there were plants uproot them and then remove the part of wall and reconstruct it by giving support to roof by heavy materials like steel girders etc, until wall has been repaired completely. 
f) For hair line cracks just remove that portion of plasters and paint and reapply the plaster with suitable lime surkhi mortar. And after proper curing apply two to three coat of whitewashing.
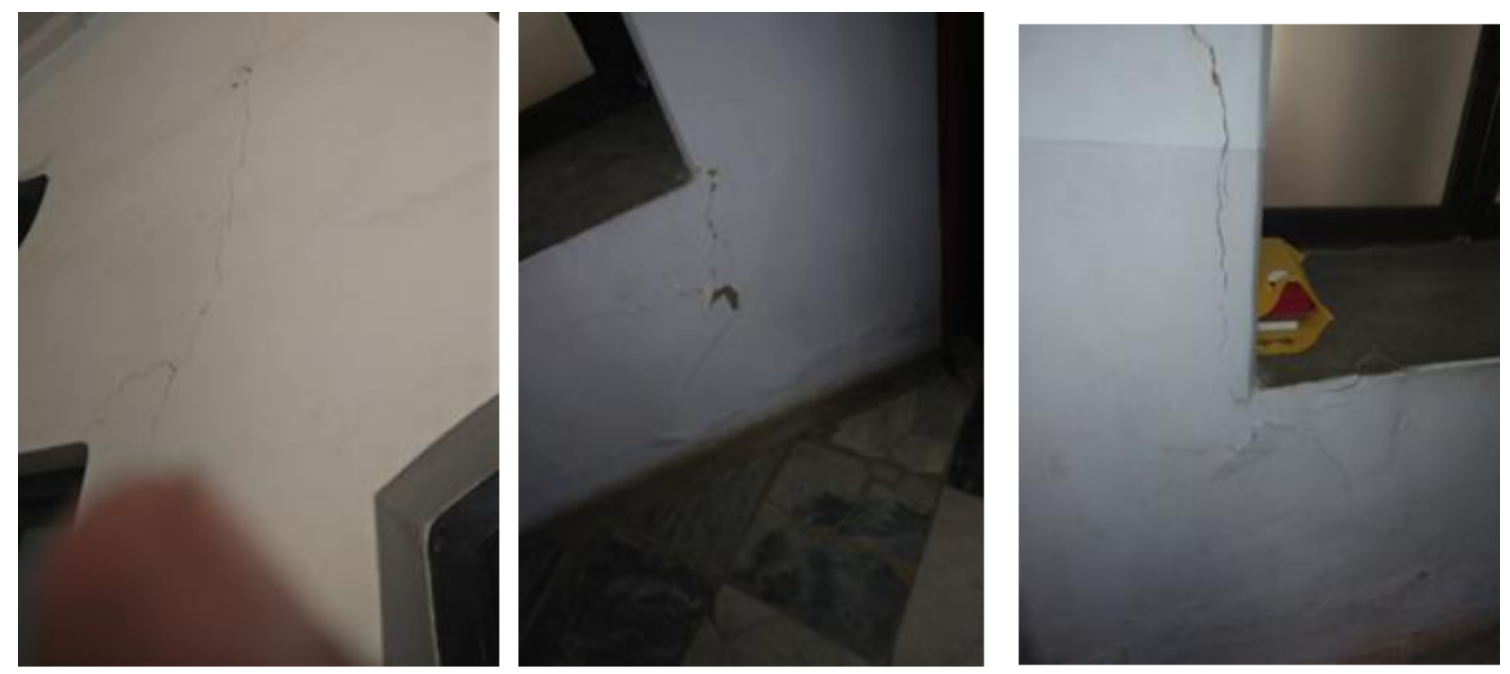

Figure 4 a) Hair line Crack

Figure 4 b) Crack due to Settlement

Figure 4 c) Structural Crack

V. Stair case damage- The wood of stair is made of Sal and the palace that portion where stair is made has been closed from many year so it has suffered a lot of damage not only due to non-maintenance but also due to age of wood and moisture effect as during raining roof damage allow water to fall over the stair. In first stair there is no attachment of stair with walls it entirely rest over wooden vertical post at regular intervals as shown in figure. The second stair case vibrates while climbing over it.

Repair of stair case

a) First of all remove all the dust and wash the area, and allow it to dry so that we can easily identify the damages.

b) There is no balusters in the stair so it is more easy to repair the thread just remove the one which is damaged and place new wood of same texture in that place.

c) We can easily repair this stair because there is access in beneath the stair and we can nails down all the destroyed riser and thread and replace them with new one.

d) Stair which are attached to walls at one end and at other where balusters are present have defect attached at walls. This can be repaired by filling lime mortar in the gap by injecting it with high pressure after force washing the gap and then applying sealant so that cracks get completely closed.

e) Stair room is completely made up of wooden materials which require proper cleaning and reapply paints which help them to live longer.

f) Wood should be chemically seasoned in order to provide resistance to termite attack because in Surguja District Woods are vulnerable to white ants. 


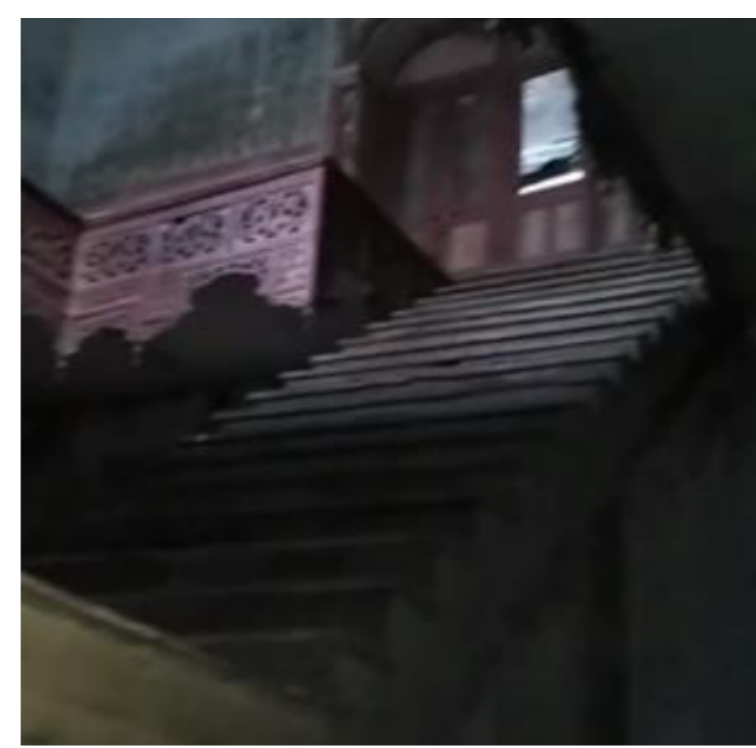

Figure 5 a) Stair case at Raghunath Palace

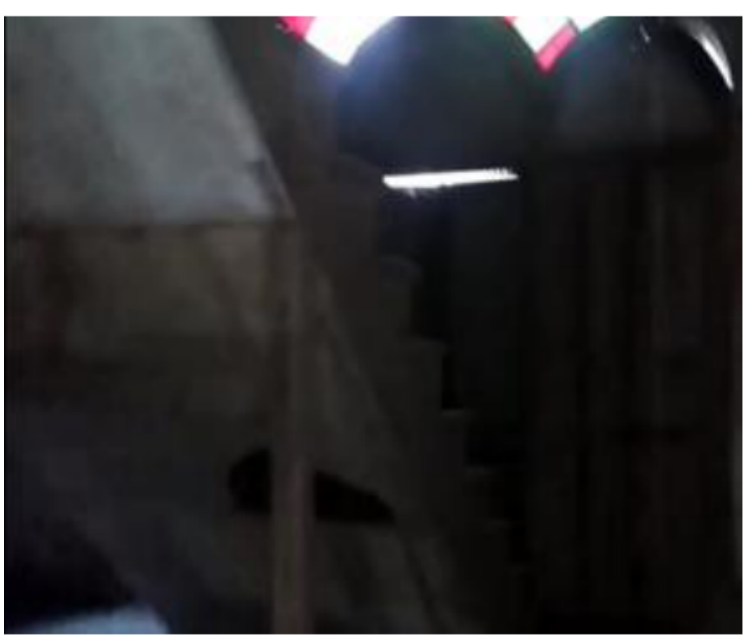

Figure 5 c) Damage in Stair At Palace

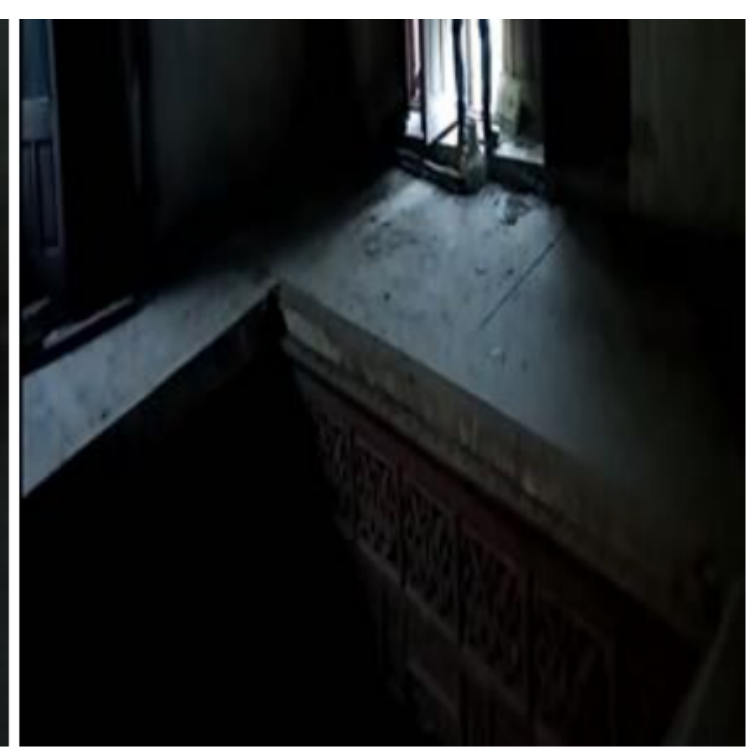

Figure 5 b) Upper portion where Stair open

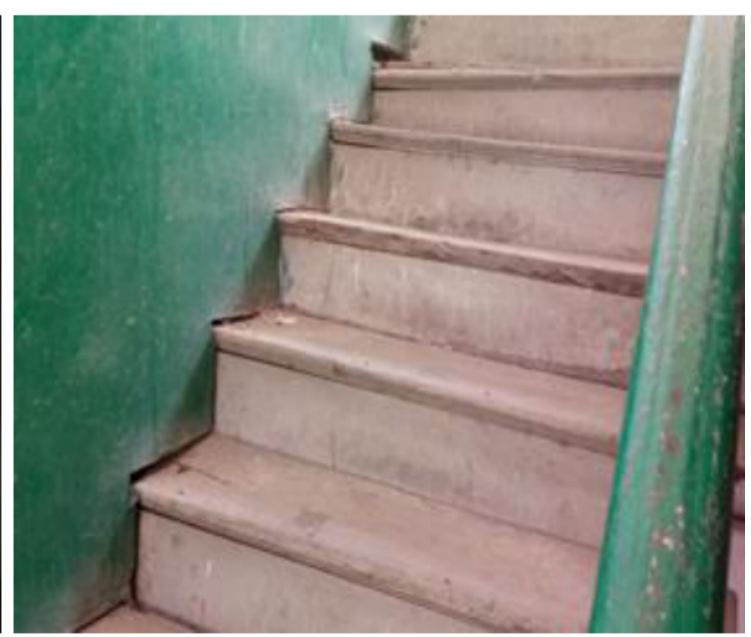

Figure 5 d) Damage in Stair at Circuit House

VI. Biological agents and Moisture damage- There are various types of biological agent which at particular seasons grow and after dying leave marks over the surface. These are even more worst then other destruction because many of has great impact on the structure. Plant growth their root interrupt the integrity of building as well as collapsing took place. Biological agent strain can be hardly removed by normal washing or cleaning so special treatment should be given to them.

Precautionary measures that we have to take while rehabilitating the structure are:-

a) First of all uproot all the plants and remove their roots.

b) Apply salt on those areas so that root gets completely destroyed.

c) Wash off the portion and then reconstruct the component with material they are made up of.

d) Find the drainage and its route and unblock it by cleaning the path so that no future algal growth could take place.

e) Use of bleaching agent along with soap solution should be done to clean the floor and walls at initial stage with high pressure. After the saturation of bleach scrub off the walls to remove the moulds and algae. And again wash it off to remove the rest of organisms. 
f) Any leaking of drainage should be closed properly so that water should not flow inside any of the rooms.

g) Apply plaster repair and whitewashing to get perfect finish.

h) Gyphosate, baking soda and vinegar, scrubbing and washing under high pressure should be used in order to remove the mosses. Fungi and algal growth.

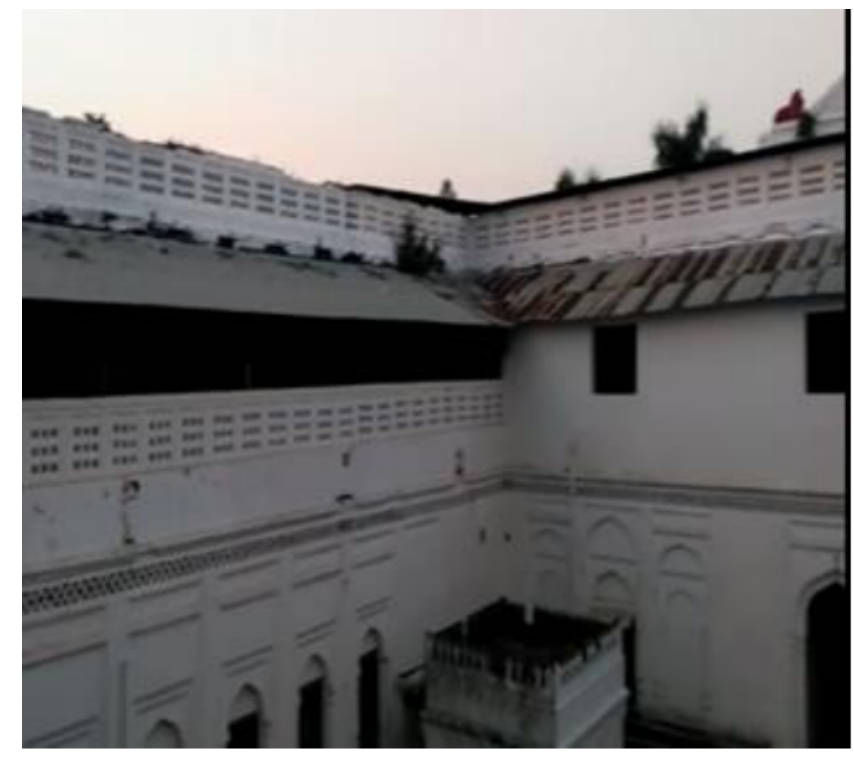

Figure 6 a) Plant growth at the edges of roofs and parapet Figure 6 a) Plants and algae attack

\section{PRECAUTIONARY MEASURE}

a) All whether skilled or non-skilled workers should be trained first because building is traditionally built and method is not practiced today which we are going to apply for renovation.

b) They should be well equipped with safety equipments.

c) Place for storage of dismantled materials which we have to use in the construction should be placed in such a manner that people would not get hurt if it falls off.

d) Some sections are very weak so at that place separate scaffolding should be brought not to be supported on the structure.

e) While dealing with mosses and fungus people should have to give importance to avoid contact of hand with mouth and eyes as they must be toxic.

f) Water proofing agents should be mixed with plastering materials in those area where exposure to moisture can be prevented.

\section{CONCLUSION}

Actually Raghunath palace is very vast it will cost a lot in restoration and require more time too. Material arrangement which will be similar to that of the existing palace is must otherwise if material deviation occurs bonding strength will get failed. Lime surkhi mortar should be prepared along with admixture of wood apple so that it should match the existing structure. Sal and Sagaun tree wood with well-seasoned and painted should be used up for place where they are required. If at certain place roof structure is to be repaired then proper anchorage should be must as building is very weak at some places. The entire exposed surface should be properly closed with thoroughly mixed mortar. At edges we should take care that marbles and tiles which have been felled of should be placed properly in order to give palace its original look. 


\section{SCOPE FOR FUTURE WORK}

On the basis of damages and their techniques used in the repair of building compare can be carried out between traditional building and modern building that how are they constructed what are the difference in economy of construction. Which one is best feasible and whose durability is better. Along with distinguishing different feature of technology used in both type of building construction.

\section{REFERENCES}

[1] Shrivastava. A, Shukla. V, International journal of research and analytical reviews (IJRAR) 7478, 2019 January Volume 6

[2] Nilendu Krishna Paul and R. P. Nanda, Shape Memory Alloy as Retrofitting Application in Historical Buildings and Monuments - A Review In Indian Perspective, International Journal of Civil Engineering and Technology (IJCIET), Volume 4, Issue 1, January- February (2013), pp. 117-125

[3] Chandra. S. Roy, International Journal for research in applied science \& Engineering Technology (IJRASET) 381, 2017 December Volume 5

[4] M. Abdel-Mooty, S. Khedr \& T. Mahfouz WIT Transactions on the Built Environment 209, 2009 Volume 109 (online)

[5] Wiggins, David The journal of the building limes forum 28, Volume 24

[6] Yuanita F.D Sidabutar, Sirojuzilam, Suwardi Lubis and Rujiman, The Influence of Building Quality, Environmental Conditions of Historical Building and Community Participation to Cultural Tourism in Medan City. International Journal of Civil Engineering and Technology, 9(3), 2018, pp. 259-270

[7] Jeffs. Paul, PJ materials consultant conservation of heritage structure \& older building

[8] D. Van. Gemert \& M. Vanden Bosch Material and structures 1651987 Volume 20

[9] Yanez, J.J. Saire, and Dr. Sen, Rajan. Repair and Rehabilitation of Structure, University of South Florida 2019

[10] Central public work department India-Conservation of Heritage Building- A guide July 2013 